\title{
Trade Liberalization and Gender Wage Gap in Mexico
}

\author{
Reyna Elizabeth Rodríguez Pérez ${ }^{1}$, David Castro Lugo ${ }^{2}$ \\ ${ }^{1}$ Faculty of Economics, Autonomous University of Coahuila, Saltillo, Mexico \\ ${ }^{2}$ Center for Socioeconomic Research, Autonomous University of Coahuila, Saltillo, Mexico \\ Email: reyna rodriguez@uadec.edu.mx,david.castro@uadec.edu.mx
}

How to cite this paper: Pérez, R.E.R. and Lugo, D.C. (2017) Trade Liberalization and Gender Wage Gap in Mexico. Modern Economy, 8, 1167-1185.

https://doi.org/10.4236/me.2017.810081

Received: July 27, 2017

Accepted: October 17, 2017

Published: October 20, 2017

Copyright $\odot 2017$ by authors and Scientific Research Publishing Inc. This work is licensed under the Creative Commons Attribution International License (CC BY 4.0).

http://creativecommons.org/licenses/by/4.0/

\begin{abstract}
The objective of the paper is to analyze the effect of trade liberalization on the wage gap by gender and its components in Mexico. For this, the behavior of the wage gap is analyzed for different regions of the country, classified according to the degree of exposure to trade liberalization. Using the quantitative methodology of Melly (2005) the breakdown of the salary gap by quantile used the micro data of the National Survey of Occupation and Employment (ENOE) for the years 2005 and 2016. The results reveal the existence of wage gap by gender in the different regions, that its magnitude differs regionally throughout distribution and that the wage gap has declined over time in all regions of Mexico, but the wage disadvantage still persists against women and this is higher in the lower deciles. Most of the differences are not explained by productive characteristics, although the proportion of inequality associated with discrimination factors declined in 2016 in relation to the previous reference year.
\end{abstract}

\section{Keywords}

Labor Economics, Wage Gap, Melly Methodology, Mexico, Decomposition, Regions

\section{Introduction}

In the last decades, Mexico has undergone great political, demographic and economic transformations, in the latter aspect one of the most relevant elements was the implementation of an economic model, characterized by a greater orientation towards the external sector, which materialized with the incorporation to the General Agreement on Tariffs and Trade (GATT) in 1986; The North American Free Trade Agreement (NAFTA) in 1994, and more than 20 more 
trade agreements in the following years.

30 years since the incorporation of Mexico into the GATT (now the World Trade Organization), major economic transformations have been generated, both spatial and sectoral, in the first case through the strengthening of geographical spaces that have advantages of localization in the new economic model and that can be defined as the region of high exposure, and in the second, the relative growth of activities that have achieved a better insertion in global value chains, such as the automotive sector and machinery and equipment in general within the manufacturing activities.

In addition to these spatial and sectoral changes, there have been changes in the Mexican labor market, one of the most important being the increasing participation of women, [1]. INEGI [2] reports that it has grown from 17.6 percent in 1970 to 41.8 percent in 2016, however, due to the greater female presence, they present unfavorable conditions: their average income level is equivalent to $80 \%$ with respect to men Rodríguez and Castro [3], and only $1.41 \%$ of women has decision-making positions as managers or public officials, 15.0 percent of them work as a professional or specialized technician, 26.9 percent are engaged in commercial activities, such as vendors [4].

In terms of wage inequality or gender pay gap, there has been a great deal of research, both for Mexico and for other countries ${ }^{1}$, measuring the magnitude of the wage gap, its components, and relevant factors, but insufficient trade openness can have on the wage gap and its components.

The motivation of this study is to explore whether trade liberalization has impacted on the gender wage gap in Mexico.

Therefore, the objective of this research is to analyze the wage gap and its decomposition along the distribution of the different regions of Mexico, under the criterion of the degree of exposure to the commercial opening in the period 2005-2016. Applying the methodology of Melly [5] based on quantile regression and its decomposition and the regionalization of Aguilera and Castro [6], with data from the Survey of Occupation and Employment (ENOE) 2005-2016.

The hypotheses to be tested are:

H1: The regions with the greatest exposure to trade liberalization have lower gender wage gaps relative to less exposed regions.

$\mathrm{H} 2$ : Women in the highest deciles will have a lower wage gap by gender in relation to the lower deciles.

H3: The unexplained component of the wage gap, which is often associated with discrimination, will be lower in regions with higher exposure relative to less exposed regions.

H4: The above behaviors are expected to show a trend towards convergence, as well as the effects, are more pronounced in 2016 compared to 2005.

The theoretical arguments underlying the above hypotheses are 1) the degree of exposure of the regions to trade liberalization increases competition between firms and workers with the same characteristics, leading to a reduction in the ${ }^{1}$ In this regard, see [3] [4] [7] [25] [32] and [33]. 
wage gap between men and women; 2) increased competition imposes higher costs on discriminatory behavior; 3 ) higher female workers have higher incomes and have more information that leads them to take better job choices and reduce wage differentials in relation to women with lower human capital and lower incomes; effects of competition are not immediate but act over time.

To test the hypotheses, the wage gap and its decomposition along the wage distribution of the different regions of Mexico will be analyzed by applying the quantitative methodology of Melly [5] based on quantile regression and its decomposition and the regionalization under the criterion of the degree of exposure to the commercial opening of Aguilera and Castro [6], with data from the Survey of Occupation and Employment (ENOE) 2005-2016. Among the main results the salary gap by gender in the different regions is highlighted, and during the study period the difference is reduced; However, there is no evidence that trade liberalization reduces the gender wage gap in Mexico and that the source of the wage gap reduction by gender over time is associated with lower discrimination due to greater competition.

The rest of the document is structured in four sections. The first presents the theoretical review on trade openness, inequality, and empirical evidence, the second presents the data and methodology, while the results are presented in section three and finalized with general conclusions and reflection.

\section{Commercial Opening, Inequality and Empirical Evidence}

\subsection{Trade Openness and Inequality}

Artecona et al. [7] mention, under Heckher-Ohlin's theory, that the increase in production could be localized in countries where the relatively abundant factor is incorporated, one of which is labor. In Mexico there is a greater proportion of unskilled and semi-qualified workers than the skilled workers, therefore the demand and the price of the most abundant factor, should be increased according to the Stolper-Samuelson theory, this relationship could reduce the wage gap between workers, in favor of the least qualified, and could result in a reduction in the wage gap for women, considering that they are located in unskilled and semi-skilled occupations, by factors such as preferences or discrimination.

Discriminatory behaviors practiced by different agents, such as consumers and producers, are reflected in the theory of taste for discrimination developed by Becker [8], according to this author, based on their preferences some individuals act as if they have an availability to pay for avoid carrying out transactions with certain groups, since this implies a subjective or psychological cost.

Artecona et al. [7], assert that there is a positive relationship between trade liberalization and reduction of the gender wage gap, since international competition could eliminate the extra wages paid by Mexican companies to men, women with the same skills, so if an employer prefers to hire male workers, above the female, he ends up paying male a salary higher than their marginal productivity, which can increase the cost of business. 
Therefore, assuming there is competition in the product market if a company does not discriminate and its rivals do, it would face higher production costs and end up losing market share or being expelled.

In summary, if we take Becker's model of reference, trade liberalization increases competition and reduces the wage gap between men and women. To the extent that economies are more exposed to trade liberalization, foreign producers will enter the most profitable domestic markets, and countries or regions less exposed to trade liberalization will be affected by competition and they will have to reduce their costs and increase their productivity to stay in the market, so they can no longer afford the luxury of discrimination. Therefore, the gender wage gap would tend to decrease in the countries or regions most exposed to trade liberalization.

Therefore, it was considered important to have an estimate of the magnitude of the wage gap and its decomposition between men and women employed in regions of Mexico according to their exposure to trade liberalization, if at all, in order to confirm if the female group obtains a lower average wage than the male population for reasons different to its productive characteristics. Faced with this concern, we present below the findings of different studies that address the problem at the international level and for Mexico.

\subsection{Empirical Evidence}

The issue has been analyzed at the international level from a regional perspective [9] for some European countries (Austria, Germany, Hungary, Switzerland, United Kingdom, Norway, Sweden, Australia); [10] for Russia, Germany and Kazakhstan; [11] for Central America (Costa Rica, Honduras, Nicaragua, El Salvador); [12] for Colombia; [13] for Shanghai and Jinan, China; [14] for Czech Republic, Hungary, Poland and Slovakia; [15] for Germany; [16] concerning communities in Spain, as well as that of [17], for 64 countries, [18] for 18 OECD member countries, results vary by region, with different methodologies and data, although most of them highlight the fact that women continue to obtain lower wages relative to men, with the same or more attributes of human capital.

The analysis of the effect of trade liberalization on the wage gap by gender in regions and/or sectors of Mexico has been addressed in different studies. Artecona et al. [7], is one of the first documents that address this aspect in the case of Mexico. Using the National Urban Employment Survey (ENEU) and the National Survey on Employment, Wages, Technology, and Training (ENESTyC), they ask if the gender wage gap in manufacturing would change with trade liberalization and if the reduction of discrimination can be attributed to the increased competition generated by trade liberalization. The study is conducted for the first phase of trade liberalization (1987-1993). The results do not allow a significant conclusion that trade liberalization narrowed the gender pay gap during the first stage of trade liberalization.

Dominguez y Brown [19], with data from ENESTyC and a more recent period (2001-2005), analyzes the gender wage behavior in the maquiladora sector. It should be noted that openness does not jeopardize the work of women since al- 
though the labor participation of women in this sector is greater than in manufacturing in general, they occupy the categories with lower wages, which would imply the presence of vertical segregation. There are wage gaps against women in different job categories, which are higher in administrative positions, and also a significant proportion of the gap is not explained by human capital endowments.

For their part, Rodríguez y Castro [3] with data from the ENEU study the behavior of the gender wage gap for the period 2000-2004 considering different regions. The results indicate the presence of gender wage gaps against women, between 15 and 25 percent, where the border region, considered the most exposed to trade liberalization, does not present the lowest levels of gender inequality. Using the Oaxaca [20] and Blinder [21] methodology, the wage gap decomposition identifies that more than 85 percent of wage differentials are not explained by observable human capital characteristics.

Tello et al. [22], with data from the ENOE and ENEU 1987-2008, analyze the relationship between wage inequality, employment structure and returns to education, applying the methodology of Melly [5], performs the decomposition of wage inequality by quantiles, as well as the analysis of individual covariances for urban areas in Mexico. In their results, they find that the differences in characteristics are much more important in the lower part (percentile 10) than in the upper part (percentile 90) of the salary distribution. In fact, some of the significant effects of the wage structure emerge in the 90th percentile.

Popli [23] performs a comparative analysis of the gender wage differential between 1996 and 2006, with data from ENIGH, distinguishing between the formal and informal labor market for Mexico. For this, it uses parametric and non-parametric methodology with log-linear conditional expectation function. The author finds that the wage gap by gender is higher in the formal labor market, although in general, the wage differentials have decreased over time (19962006) in both markets, glass ceiling effect in the formal, with an increase in the unexplained part mainly in the upper tail of the income distribution.

For their part, Arceo and Campo [24] analyze the gender gap for the period 1990-2010, using the Population Censuses and find that on average there is a decrease in inequality in the period. Using the semiparametric methodology proposed by DiNardo et al. [25] to break the gap and correct for the selection bias of women in the labor market, find that most of the wage gap is due to the effect of prices rather than characteristics, however, by correcting for bias the wage gap would have been higher for women with low education and in low quantiles.

In another study, Rodríguez and Castro [26], for the case of manufacturing, a sector with greater foreign direct investment (FDI), in the cities of Saltillo and Hermosillo, belonging to border states, with data from ENOE 2005-2011, using the methodology of Oaxaca [20]-Blinder [21], find that in Saltillo and Hermosillo the differences are 26.0 and 27.0 percent on average for the period in favor of men, and the subsequent decomposition of income confirmed that three- 
quarters of the income gap in these metropolitan areas are associated with the unexplained part of the characteristics.

Castro et al. [27] analyze wage discrimination by gender, in the manufacturing industry of the northern border of Mexico during the period 2005-2011, with information from ENOE. They use the Oaxaca [20]-Blinder [21] technique and correct for selection bias, their results indicate that at both the northern and national border levels in industry, women have wage perceptions, approximately 13 percent less, with respect to men for reasons other than their productive attributes and also that the differences between the two geographical references are not relevant which would indicate that the behavior of the wage gap by gender in the manufacturing sector does not present modifications in the regions with greater degree of competition in relation with the rest of Mexico.

For its part, Rodríguez [4], with the National Survey of Employment and Employment (2005 and 2015), with the method of Melly [5], for Mexico and its regions, according to its exposure to trade liberalization, finds that inequality Salary by gender, has declined, although this is against women. Most of the differences are not explained by the productive characteristics, accentuating in the upper part of the wage distribution, in the regions most exposed to the commercial opening.

In summary, the review of empirical evidence outlined in this section covers from 1987 to 2015, considering different sources of information, economic sectors, cities, and regions, as well as with different methodological approaches. In general, the documents conclude that during the period of commercial and subsequent opening, the wage gap persists against women, although it is observed that it decreases over time, as the non-explaining part (associated with gender wage discrimination) contributes to explain most of the wage gap. On the other hand, the results of the studies reviewed do not provide elements that indicate that trade liberalization favored the reduction of gender wage inequality in Mexico. Finally, the review allows identifying the insufficiency of recent studies that analyze the effects of trade liberalization on gender pay inequality using methodologies that carry out a measurement and decomposition of the gender wage gap along the distribution.

\section{Data and Methodology}

\subsection{Data}

The study is based on the analysis of the individual data of the ENOE carried out quarterly by the National Institute of Statistics and Geography (INEGI). In the present work, the third quarter of 2005 and 2016 is considered, which avoids the effects of seasonal factors and which is intended to cover the most recent available information period of the survey and, at the same time, to extend the analysis of studies similar antecedents.

The study population is women and men subordinate and paid between 16 and 65 years of age. Years of education are used, as well as the potential expe- 
rience of individuals, as well as the monthly hourly wage deflated with the Consumer Price Index (CPI) 2016.

There are different studies that classify Mexico, Hanson [28] and Gutierrez [29], however, this study considered regionalization proposed by Aguilera and Castro [6], considered to be the most complete and in accordance with the analysis that is desired, since they classify the states that have high, medium or low exposure to the commercial opening, through their specialization Productive and exporting and importing capacity based on the estimation of localization and export coefficients, calculated with GDP data at 2003 prices for the period 2005-2011. The authors selected as high-exposure states those whose rank remained mostly in the upper third in the measures of participation of manufacturing industries in state GDP, foreign direct investment flows, and grosscensus value per capita of the manufacturing sector, the percentage of manufacturing employment over total state employment and distance to the United States. On the contrary, the entities that remained in the lower third were considered as low exposure, and therefore, the remaining ones were of medium exposure, the Map 1 shows the spatial distribution of the regions.

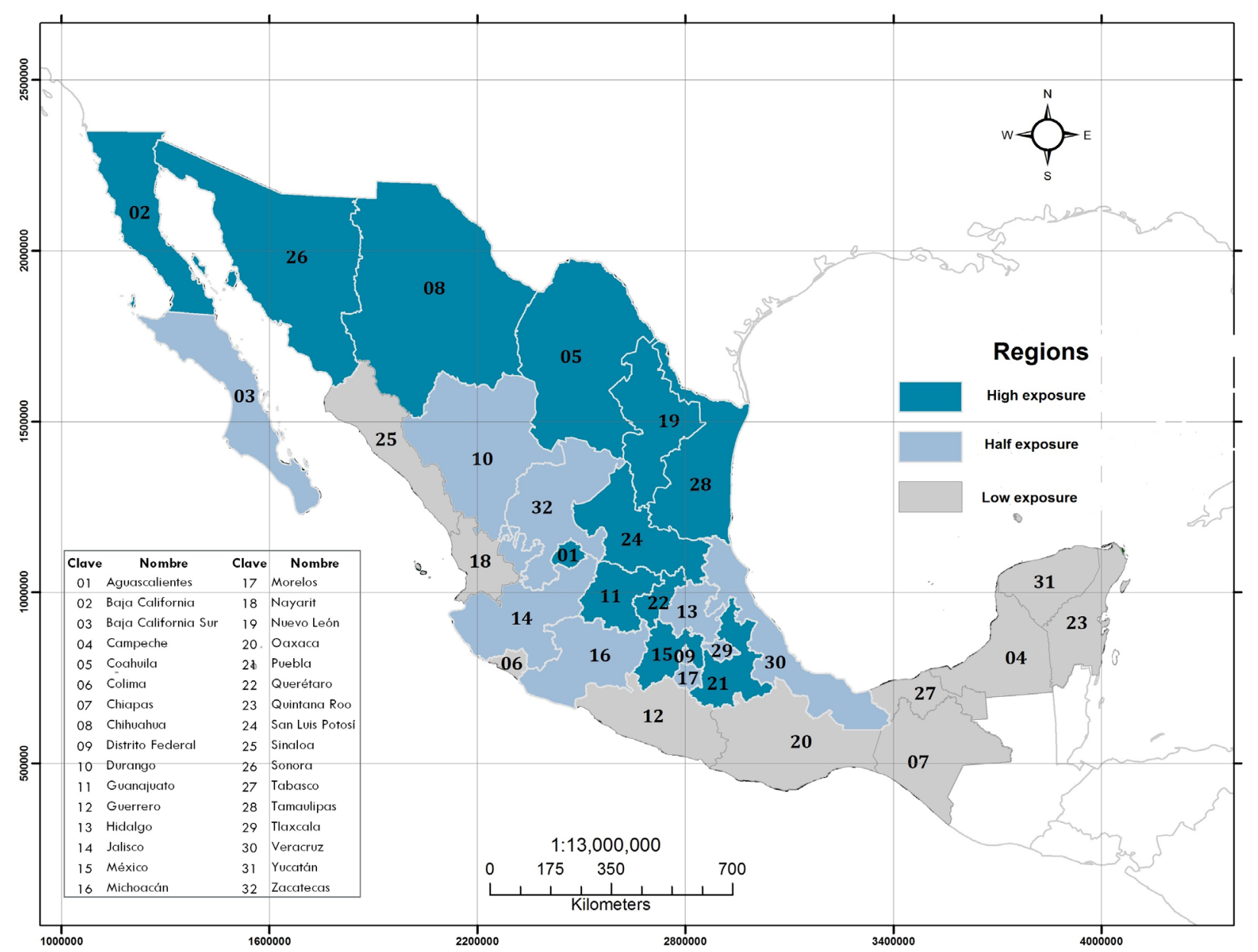

Source: Aguilera and Castro 2016.

Map 1. Spatial distribution of the states that make up the regions according to their exposure to trade liberalization in Mexico. 


\subsection{Decomposition of the Differences in the Wage Distribution by Quantiles}

To meet the objective of this research, wage equations are estimated using a quantile regression technique, for different segments of the wage distribution, in order to decompose the wage differences between women and men, in their components explained and not explained by the characteristics of human capital.

Koenker and Bassett [30] and Koenker and Hallock [31], propose the technique of quantile regression, showing the wage determinants in different segments of the distribution. Dueñas et al. [32] mention that the purpose of the quantile regression technique is to approximate the conditioned mean and other quantile response variables as dispersion measures, such as variance, standard deviation, among others. The same author points out that this type of estimation is appropriate when the behavior that is attempted to study does not present the same patterns in each and every one of the parts of the distribution or if it includes atypical cases of interest.

Melly [5] uses Mincer's regression technique [33] to perform the quantile analysis, based on Koenker and Bassett [30] and Koenker and Hallock [31], from the counterfactual approach of Oaxaca-Blinder [20] and [21].

Melly [5] analyzes the effects of covariance on wage inequality and its decomposition in each of the quantiles, where it shows whether such differences are due to the effects on the characteristics of the coefficients. The quantile regressions are calculated separately for each year of study for $\hat{q} \operatorname{con} \theta=0.10$, $0.20,0.30,0.40,0.50,0.60,0.70,0.80,0.90$.

It is assumed that the quantiles of $Y$ are linear to $X$ and the parametric general extension is direct. An estimator of the unconditional distribution function is presented in the presence of covariates, which is used to decompose the distribution differences, which is analogous to the Oaxaca-Blinder decomposition [20] and [21].

In Equation (1), $Y$ reflects the explanatory variable of the logarithm of hourly wages, $X$ are the explanatory variables for the individual $i$, in this case, education and potential experience $F_{Y}(q)$ and is the cumulative function of the variable Y of $q, F(y) q$, represents the density of $Y$, at the same point, $F(\theta)$ and-1 reflects the inverse of the distribution function, commonly called the quantile function, evaluated at $0<\theta<1 . \quad F_{y}\left(q \mid X_{i}\right)$, represents the unconditional accumulation of the distribution function $\mathrm{Y}$ evaluated at $q$, which receives $X=X_{i}$.

$$
\hat{q}_{t}(\theta)=\inf \left\{q: n_{t}^{-1} \sum_{i: T_{i}=t} \hat{F}_{Y(t)}\left(q \mid X_{i}\right) \geq \theta\right\}
$$

The quantile of unconditional distribution can be estimated considered by a simple quantile $\hat{q}_{t}(\theta)$ is more precise than the simple quantile. However, it is a counterfactual estimator; it is used to decompose the differences in distribution and estimate the effects by quantile.

$$
\hat{q}_{c}(\theta)=\inf \left\{q: n_{t}^{-1} \sum_{i: T_{i}} F_{Y(0)}\left(q \mid X_{i}\right) \geq \theta\right\}
$$


The disparity in the logarithm of hourly wages is primarily explained by differences in characteristics (continuing education and potential experience) between men and women. The second term is the part of the inequality associated with the difference in wages to the characteristics, that is to say, it corresponds to the part of the inequality of the logarithm of wages, due to the differences (quantile) of the characteristics between men and women. This is explained by the unconditioned quantile function based on a binary treatment of $t$ (women 0 and men 1) and would reflect the counterfactual function.

$$
\hat{q}_{1}(\theta)-\hat{q}_{0}(\theta)=\left[\hat{q}_{1}(\theta)-\hat{q}_{c}(\theta)\right]+\left[\hat{q}_{c}(\theta)-\hat{q}_{0}(\theta)\right]
$$

The decomposition of the wage differential with the Oaxaca [20]) and Blinder ([21] technique, supposes the absence of discrimination and assumes that the effects generated by human capital endowments should be identical for both groups; so that differences in wages only reflect disparities in human capital endowments, and thus in labor productivity.

To explain changes in wage structure, standard economic theory focuses on average wage dynamics rather than changes in the wage distribution, thus ignoring differences in the lower or upper part of the wage distribution. In addition, average wage statistics can hide important functions in the wage structure. The contribution of this research is to obtain wage differentials throughout the distribution, by quantiles at the regional level according to their exposure to the commercial opening in Mexico in the recent decade.

\section{Results}

\subsection{Descriptive Statistics}

Table 1 presents the occupational, salary and socio-demographic information of the employed, subordinate and paid population of Mexico and its different regions, according to their exposure to the commercial opening for the years 2005-2016. Considering the structure and behavior of the different variables, it is possible to highlight some relevant elements. The region with the highest exposure is the one with the highest real wage per hour, although the workers in this region have fewer years of education than the rest, less participation of women and a greater presence of the manufacturing sector. During the period under review, average real hourly remuneration decreased, especially in the region with the highest exposure, resulting in greater regional convergence. Wome's labor participation increased in all regions, and the presence in the region of high exposure was even lower. In relation to the average years of schooling, the regional gaps were widened, given that the slower advance in the region of greater exposure, the same behavior is observed in relation to the occupational structure, where the regions of medium and low exposure decreased their presence in the manufacturing sector while that of high exposure remained unchanged. In the rest of the sectors, the services of restaurants and lodging, as well as those related to professional and financial services increased their participation to the detriment of the extractive industry, commerce and government. From the 
Table 1. Average variables for Mexico and regions according to their exposure to trade liberalization 2005-2016.

\begin{tabular}{|c|c|c|c|c|c|c|c|c|}
\hline & \multicolumn{4}{|c|}{2005} & \multicolumn{4}{|c|}{2016} \\
\hline & \multicolumn{4}{|c|}{$\begin{array}{l}\text { Regions according to their } \\
\text { exposure to trade liberalization }\end{array}$} & \multicolumn{4}{|c|}{$\begin{array}{l}\text { Regions according to their } \\
\text { exposure to trade liberalization }\end{array}$} \\
\hline & México & High & Medium & Low & México & High & Medium & Low \\
\hline $\begin{array}{l}\text { Hourly wage (mexican pesos } \\
\text { 2016) }\end{array}$ & 42.38 & 45.26 & 40.91 & 41.75 & 37.09 & 38.79 & 36.10 & 37.44 \\
\hline Hours & 44.80 & 44.66 & 44.80 & 45.13 & 44.26 & 44.21 & 44.27 & 44.31 \\
\hline Married & 0.604 & 0.603 & 0.605 & 0.602 & 0.589 & 0.607 & 0.576 & 0.603 \\
\hline Head of household & 0.461 & 0.464 & 0.460 & 0.461 & 0.445 & 0.457 & 0.436 & 0.455 \\
\hline Educational years & 10.15 & 10.03 & 10.18 & 10.34 & 10.99 & 10.80 & 11.03 & 11.23 \\
\hline Experience & 19.75 & 19.35 & 20.12 & 19.06 & 20.90 & 20.41 & 21.37 & 20.00 \\
\hline Full time & 0.750 & 0.774 & 0.742 & 0.723 & 0.750 & 0.768 & 0.748 & 0.720 \\
\hline Qualified & 0.380 & 0.350 & 0.389 & 0.412 & 0.462 & 0.418 & 0.479 & 0.492 \\
\hline Sex & 0.607 & 0.624 & 0.601 & 0.591 & 0.583 & 0.596 & 0.578 & 0.572 \\
\hline $14-25$ & 0.238 & 0.250 & 0.228 & 0.253 & 0.201 & 0.220 & 0.189 & 0.212 \\
\hline $26-35$ & 0.277 & 0.281 & 0.273 & 0.279 & 0.252 & 0.247 & 0.254 & 0.260 \\
\hline $36-45$ & 0.254 & 0.252 & 0.256 & 0.248 & 0.252 & 0.255 & 0.248 & 0.257 \\
\hline $46-55$ & 0.161 & 0.153 & 0.167 & 0.155 & 0.195 & 0.190 & 0.200 & 0.181 \\
\hline $56-65$ & 0.0700 & 0.0633 & 0.0748 & 0.0655 & 0.100 & 0.0880 & 0.109 & 0.0897 \\
\hline High region & 0.315 & & & & 0.303 & & & \\
\hline Medium region & 0.563 & & & & 0.568 & & & \\
\hline Low region & 0.121 & & & & 0.129 & & & \\
\hline $\begin{array}{c}\text { Agriculture, forestry and } \\
\text { fishing }\end{array}$ & 0.00857 & 0.00916 & 0.00708 & 0.0139 & 0.00726 & 0.00687 & 0.00597 & 0.0138 \\
\hline $\begin{array}{c}\text { Extractive industry and } \\
\text { electricity }\end{array}$ & 0.00743 & 0.00639 & 0.00688 & 0.0127 & 0.00581 & 0.00563 & 0.00497 & 0.00993 \\
\hline $\begin{array}{l}\text { Manufacturing } \\
\text { industry }\end{array}$ & 0.189 & 0.253 & 0.171 & 0.102 & 0.176 & 0.251 & 0.156 & 0.0861 \\
\hline Building & 0.0788 & 0.0853 & 0.0726 & 0.0904 & 0.0805 & 0.0846 & 0.0754 & 0.0936 \\
\hline Commerce & 0.226 & 0.206 & 0.235 & 0.233 & 0.216 & 0.203 & 0.222 & 0.219 \\
\hline $\begin{array}{c}\text { Restaurants and } \\
\text { accommodation services }\end{array}$ & 0.0684 & 0.0634 & 0.0624 & 0.109 & 0.0892 & 0.0791 & 0.0861 & 0.127 \\
\hline $\begin{array}{l}\text { Transport, } \\
\text { communications, } \\
\text { mails and storage }\end{array}$ & 0.0728 & 0.0608 & 0.0812 & 0.0648 & 0.0676 & 0.0565 & 0.0757 & 0.0582 \\
\hline Financial profesional services & 0.0837 & 0.0796 & 0.0886 & 0.0718 & 0.103 & 0.0877 & 0.114 & 0.0916 \\
\hline Social services & 0.0862 & 0.0796 & 0.0890 & 0.0906 & 0.0827 & 0.0792 & 0.0816 & 0.0960 \\
\hline $\begin{array}{l}\text { Miscellaneous } \\
\text { services }\end{array}$ & 0.120 & 0.111 & 0.123 & 0.127 & 0.118 & 0.109 & 0.119 & 0.131 \\
\hline Government & 0.0601 & 0.0457 & 0.0628 & 0.0847 & 0.0545 & 0.0383 & 0.0586 & 0.0744 \\
\hline Observations & $16,348,681$ & $5,156,261$ & $9,207,502$ & $1,984,918$ & $18,006,488$ & $5,463,979$ & $10,219,252$ & $2,323,257$ \\
\hline
\end{tabular}

Source: Own elaboration based on ENOE data, respective years. 
information presented in Table 1, it can be established that during the period 2005-2016 in the different regions of Mexico there is a process of regional convergence downward in hourly wage rates, despite the widening of the differences in the endowments of years of average schooling and in the occupational structure, especially regarding the participation in manufacturing activities.

The descriptive information of the data allows identifying the existence of regional differences relevant in the labor markets. In the region with the highest exposure, the real hourly wage is higher, as it would correspond to a region with greater labor competition due to a strong link with the foreign market. The information also recorded a fall in real hourly wages in the period (2005-2016), a fact that is registered in all regions. On the other hand, in the region with the greatest exposure, the manufacturing sector has a greater participation, and in this region, workers have fewer years of education than the rest of the regions, which seems to support the argument of the Stolper-Samuelson theorem, Although the lower relative participation of women in this regional labor market seems not to go in that direction.

In the following section, a comparison of the wage gap by gender in each one of the regions of Mexico is made, as well as its decomposition.

\subsection{Gender Pay Gap and Decomposition}

The review of previous studies on the wage gap in Mexico indicate that: 1) gender pay gaps are relevant, 2) the measurement and decomposition of wage inequality has been done mainly through methodologies that consider only the mean values of the distribution, 3 ) there are few studies that incorporate recent data and analyze the behavior of the wage gap in the last decade, 4) regional analyses that include spatial delimitations associated with the degree of exposure to the outside have been made without considering a product regionalization of a methodological exercise, and 5) the origin of wage discrimination is not sufficiently explained, aspects that are covered in this document and constitute the main contribution of the same.

The first objective is to determine the gender wage gap by considering different points of the distribution since it is reasonable to assume that the gender wage gap does not necessarily have the same magnitude as its average value. Figure 1 presents the behavior of the gender wage gap for 2005 and 2016, considering information by deciles.

From the information provided by the Figure 1 can identify some relevant elements. 1) It can be seen that the wage gap is different by deciles, a fact that justifies extending the analysis beyond the mean values; 2 ) the wage differential is in favor of men, which is in line with previous studies; 3 ) the wage difference is higher in the lower deciles, a fact that can be interpreted as evidence supporting the presence of sticky floor; 4) there are differences in the regional wage gap, which justifies addressing the wage gap from a regional perspective; and 5) the wage gap has declined over the last decade in all regions, although the magnitude 


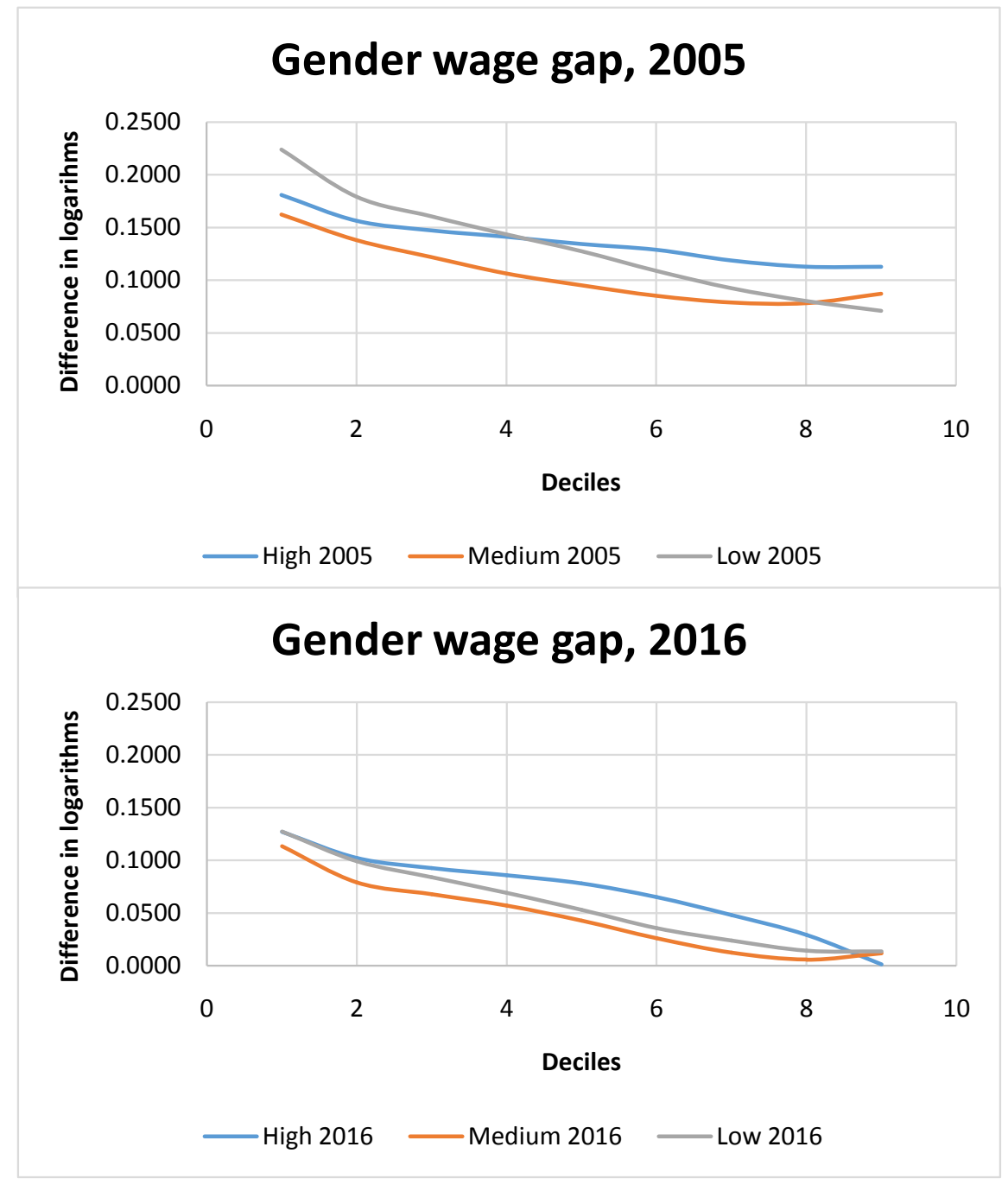

Figure 1. Mexico and regions by the level of exposure. Wage gap by sex, by deciles, 2005 and 2016.

of the reduction Is different by regions and deciles, highlighting the higher deciles of the region of high exposure.

In relation to the first hypothesis, based on the information available, there do not seem to be any elements to support compliance, since the region with the highest exposure does not present the lowest relative wage gap by gender. These results go online as found by [7] [20] and Castro et al. (2015), since they do not find sufficient evidence to indicate a decrease in the wage gap in favor of women in the regions and sectors most exposed to trade liberalization.

On the other hand, it can be observed that the wage gap is significantly lower in the upper deciles relative to the lower part of the distribution, a fact that provides evidence in favor of hypothesis 2 , and that it would not find correspondence with Popli [23] and Tello et al. [22] who hold the existence of a glass ceiling, however, is coincident with Rodríguez [4], finding a greater inequality in the low deciles of the salary distribution. On the other hand, in relation to the temporal 
behavior of the wage gap along the distribution (hypothesis 4), it is possible to state that for 2016, the region with the greatest exposure, is not the geographical reference with the lowest wage gap, however, There is a reduction compared to that observed in 2005 and a smaller relative difference with respect to the rest of the regions, also observing the behavior of the differences in the wage gap between the lower and upper deciles for the years 2005 and 2016, it is possible to affirm That these are greater for the last reference year, a fact that contributes elements of support to the hypothesis 4 , thus the hypothesis finds partial support.

Once the gender wage gap in each of the regions has been exposed, the characterization and coefficients are decomposed using the quantile regression technique by Melly [5].

In order to identify the contribution of the characteristic effects (human capital endowments) and those related to the coefficients (yields to endowments), the wage gap by deciles for the year 2005 is decomposed and presented in the Figure 2.

From the information provided by the decomposition can be established: 1) the wage gap is the product of the two effects found, where the corresponding coefficients are dominant in all regions, 2) the contribution of the characteristic effects and coefficients To the total wage gap is different by deciles, with the highest coefficient effect at the top of the distribution, even higher than the total wage gap, which is compensated for by negative characteristic effects, indicating that women have more human capital than the men; 3) the behavior of the effects coefficients and characteristics are different between regions throughout the distribution, while in the region of high exposure the coefficient effect is increasing by deciles, in the region of medium exposure the effect remains stable
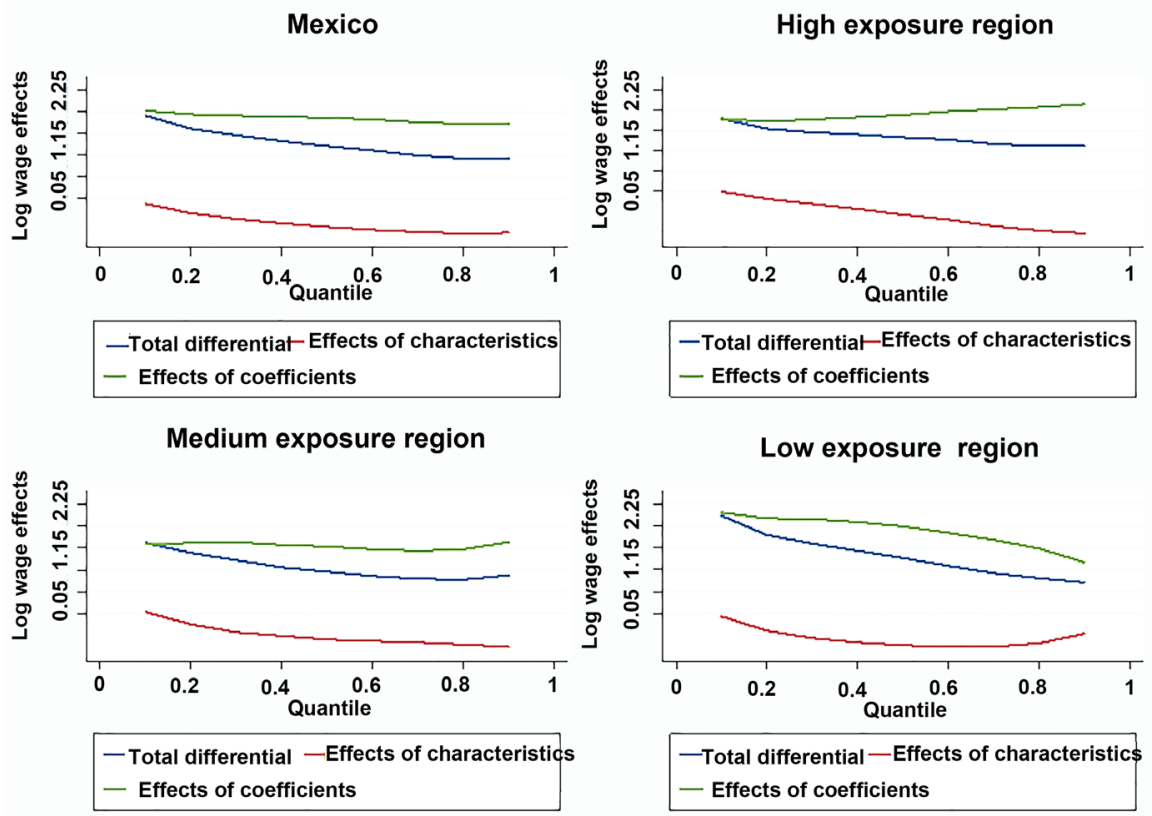

Figure 2. Decomposition of the hourly wage differential in the distribution by quantiles in Mexico and regions according to their exposure to trade liberalization. 2005. 
and in the less exposed the coefficient decreases, so there seems to be a direct relationship between exposure to the openness and magnitude of the coefficient effect along the distribution, indicating an inverse behavior than expected a priori.

Figure 3 presents the breakdown of the wage gap for 2016, general and by region, which indicates that for this reference year, there is a behavior different from that observed in 2005, among which we can highlight: 1) the main component of the reduction of the temporary wage gap corresponds to the coefficient effect; especially for the region of greatest exposure, which changes the direction of the coefficient effect, 2) the contribution of the coefficient effect to the wage gap is reduced for the higher deciles, and 3) the differences in the behavior of the wage gap and its components explained (effect characteristics) and unexplained (effect coefficients) are reduced between regions for the year 2016, a fact that may be expected if we consider that the permeability of the regions to the external aperture model is increasing over time.

From the information provided by the breakdown of the wage gap by sex for the different regions, it is possible to affirm that there are no elements available to support that the unexplained component (coefficient effect) of the wage gap decomposition is smaller In the region of greatest exposure, which rejects hypothesis 3 , indicating that the greater competition generated by trade liberalization, at least in the case of Mexico, does not constitute a strong enough element to reduce wage discrimination by gender Associated to the coefficients), an outcome that is shared by Artecona and Cunningham [7].

It is important to note that there is a reduction of the coefficient effect on the wage gap over time and a greater convergence with the rest of the regions, which would partially support the hypothesis 4 .
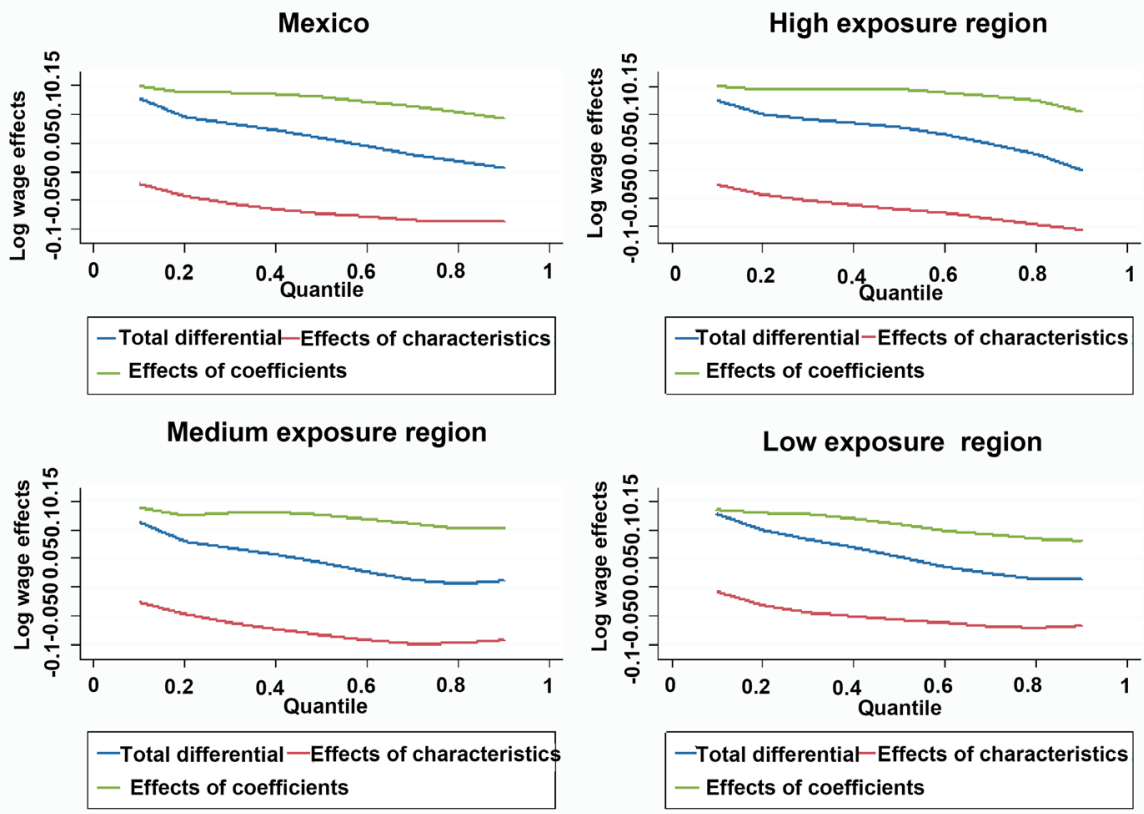

Figure 3. Decomposition of the hourly wage differential in the distribution by quantiles in Mexico and regions according to their exposure to trade liberalization, 2016. 
In general, it can be deduced that in Mexico and the different regions, gender wage gaps have been reduced from 2005 to 2016, where most of the reduction is not explained by productive characteristics, but by unexplained factors, although this element continues to explain most of the wage gap.

The evidence found is in line with the findings of Popli [23], Arceo and Campos [24], Tello et al. [22], as well as Rodríguez [4], since they indicate the existence of a decrease of the inequality in favor of the women, although in breaking down the gap in characteristics and price, they find that most of the differences are due to the effect of the prices. Popli [23] reveals evidence of "glass ceiling" and Arceo and Campos [24], from a stable pattern of "sticky floor" and a decreasing "glass ceiling", Tello et al. [22]. On the other hand, observes "sticky floor" and "glass ceiling" in its results: in this research the results generally indicate that the yields are higher are the lower deciles of the distribution, especially for 2016, a fact that could be indicating the presence of sticky floor.

\section{Conclusions}

The objective of the paper is to analyze the effect of trade liberalization on the wage gap by gender and its components in Mexico. For this, the behavior of the wage gap is analyzed for different regions of the country, classified according to the degree of exposure to trade liberalization. Using the methodology of Melly [5] made the breakdown of the wage gap by quantile used micro data of the National Survey of Occupation and Employment (ENOE) for the years 2005 and 2016.

The results reveal the existence of a gender wage gap in the different regions that its size differs regionally, along with the distribution and that the wage gap has diminished over time in all regions of Mexico, but the wage disadvantage against women and this is higher in the lower deciles. Most of the differences are not explained by productive characteristics, although the proportion of inequality associated with discrimination factors declined in 2016 in relation to the previous reference year.

In the document, different hypotheses were put forward to contrast the effect of trade liberalization on the wage gap and its components, particularly on the one related to differences in returns, and which is associated with elements of discrimination to explain the wage gap.

The first hypothesis argues that the regions with the greatest exposure to trade liberalization have lower gender wage gaps relative to less exposed regions.

In relation to this first hypothesis, based on the available information, there does not appear to be any elements to support its compliance, since the region with the highest exposure does not present the lowest relative gender pay gap for any of the years, a result that is shared by previous studies that considering different periods, sources of information and methodologies do not find sufficient evidence to maintain that the commercial opening favors the women in the remunerations and reduces the wage gap by gender.

The second hypothesis states that women in the highest deciles will have a lower gender wage gap in relation to lower deciles. In this respect, the data pro- 
vide evidence in favor of this hypothesis, given that the wage gap is lower in the upper deciles of the distribution, a fact that is fulfilled for the two reference years, a result that differs from previous studies where they find elements to sustain that In the case of Mexico, the so-called "glass ceiling" phenomenon is presented in the wage distribution by gender.

Hypothesis 3 states that the unexplained component of the wage gap, which is often associated with discrimination, will be lower in regions with higher exposure relative to less exposed regions. In this respect, the results indicate that, based on the information provided by the breakdown of the gender wage gap for the different regions, it is possible to affirm that there are no elements available to support that the unexplained component (coefficient effect) of the wage gap decomposition is lower in the region of greatest exposure, which rejects hypothesis 3, a fact that can be interpreted as an indication that the greater competition associated with trade liberalization, at least for the case of Mexico, is not a strong enough element to reduce gender pay discrimination, a result that is shared by previous studies.

Finally, hypothesis 4 states that the above behaviors (hypotheses $1-3$ ) will be the most pronounced effects in 2016 in relation to 2005 and that a trend towards regional convergence will be observed, given the permeability of the effect of trade opening over time in the different regions. In this respect, the results of the wage gap estimates and their decomposition do not provide elements for not rejecting hypotheses 1 and 3, which would not confirm this hypothesis, there are elements to affirm the presence of greater convergence in wage gaps regional, and this would be partially fulfilled.

The reduction in the wage gap in all regions regardless of their degree of exposure is possibly indicating the presence of other factors, not necessarily linked to trade liberalization, such as the policy of wage restraint, among others, which are affecting on the behavior of the gender wage gap homogeneously throughout Mexico.

The document provides elements that allow a better knowledge about the effects of trade liberalization on the wage gap and its components along the wage distribution for the case of Mexico in the last decade. The results do not seem to contribute to the fact that trade liberalization generates a reduction in the gender pay gap and that the most relevant component of the reduction is associated with performance factors, which are linked to discrimination; however, it is pertinent to recognize the limitation that for the study requires considering in the analysis two reference years, it would be desirable to include more years of the study. The above identifies the need to advance in the thematic, with the purpose of having more knowledge of the effect of the commercial opening on the wage gap and its decomposition. In the analysis developed in this document, it considers salaried and remunerated workers from all economic sectors (public and private); however, a reasonable extension of this line of research would be to reduce the analysis to the manufacturing sector, since it is the economic activity most directly related to trade liberalization; a second extension would be to per- 
form a decomposition of the different components associated with the endowment of human capital to identify the contribution and evolution in the explanation of the wage gap along the distribution.

\section{References}

[1] Instituto Nacional de Estadística y Geografía (2010) Population Census. INEGI, Aguascalientes.

[2] Instituto Nacional de Estadística y Geografía (2005-2015) National Survey of Occupation and Employment. INEGI, Aguascalientes.

[3] Rodríguez, R. and David, C. (2014) Discriminación salarial de la mujer en el mercado laboral de México y sus regiones. [Gender Wage Discrimination in the Labor Market in México and Its Regions.] Economía Sociedad y Territorio, 46, 655686. https://doi.org/10.22136/est002014392

[4] Rodríguez, R.E. (2018) Brecha salarial por género en México. Desde un enfoque regional, según su exposición a la apertura comercial 2005-2015. [Gender Pay Gap in Mexico: From a Regional Perspective, According to Its Exposure to the 20052015 Trade Opening.] Noesis, 27, 19-38. https://doi.org/10.20983/noesis.2018.2.2

[5] Blaise, M. (2005) Descomposition of Differences in Distribution Using Quiantile Regression. Labour Economic, 12, 577-590. https://doi.org/10.1016/j.labeco.2005.05.006

[6] Aguilera, A. and Castro, D. (2016) La dinámica regional y el proceso de apertura comercial en México. [Regional Dynamics and the Process of Trade Opening in Mexico.] In: Castro, D. and Rodríguez, R., Eds., Mercado laboral en México: Situación y desafíos, Universidad Autónoma de Coahuila, De Laurel, 49-80.

[7] Artecona, R. and Cunningham, W. (2002) Effects of Trade Liberalization on the Gender Wage Gap in Mexico. Policy Research Report on Gender and Development Working Paper Series, No. 21, World Bank, Washington DC. http://documents.worldbank.org/curated/en/860271468049793708/Effects-of-tradeliberalization-on-the-gender-wage-gap-in-Mexico

[8] Becker, G. (1967) The Economic of Discrimination. 2nd Edition, The University of Chicago Press, 167.

[9] Blau, F. and Lawrence, K. (1996) Wage Structure and Gender Earnings Differentials: An Internationals Comparison. Economics, 250, 29-62. https://doi.org/10.2307/2554808

[10] Semykina, A. and Susan, L. (2010) Analyzing the Gender Pay Gap in Transition Economies: How Much Does Personality Matter? Human Relations, 63, 447-469. https://doi.org/10.1177/0018726709339094

[11] Enamorado, T., Ana, C.I. and Hugo, Ñ. (2009) Gender Wage Gaps in Central American Countries: Evidence from a Non-Parametric Approach. Inter-American Development Bank, Working Papers Series 111, 1-32.

[12] Galvis, L. (2011) Diferencias salariales por género y región en Colombia: Una aproximación con regresión por cuentiles. [Wage Differences by Gender and Region in Colombia: An Approach to Regression by Quantiles.] Revista de Economía del Rosario, 13, 235-277.

[13] Liu, P.-W., Xin, M. and Zhang, J. (2000) Sectoral Gender Wage Differentials and Discrimination in the Transitional Chinese Economy. Journal of Population Economics, 13, 331-352. https://doi.org/10.1007/s001480050141

[14] Mysikova, M. (2012) Gender Wage Gap in the Czech Republic and Central Euro- 
pean Countries. Prague Economic Papers. The University of Economics Prague, Vol. 3, 328-346. https://doi.org/10.18267/j.pep.427

[15] Hirsch, B. (2013) The Impact of Female Managers on the Gender Pay Gap: Evidence from Linked Employer-Employee Data for Germany. Economics Letters, 119, 348-350.

[16] Ñopo, H., Nancy, D. and Johanna, R. (2011) Gender Earnings Gaps in the World. Institute for the Study of Labor (IZA), 5736.

[17] Del Rio, C., Carlos, G. and Olga, C. (2008) Pobreza y Discriminación salarial por razón de género en España.Hacienda publicaespañola. [Poverty and Gender Discrimination in Spain.] Revista de Economia Publica, 184, 67-87.

[18] Wolsczak-Derlacz, J. (2013) Mind the Gender Wage Gap the Impact of Trade and Competition on Sectoral Wage Differences. The Word Economy, 36, 437-464. https://doi.org/10.1111/twec.12026

[19] Domínguez, L. and Flor, B. (2010) Trade Liberalization and Gender Wage Inequality in Mexico, Feminist Economics, 16, 53-79. https://doi.org/10.1080/13545701.2010.530582

[20] Oaxaca, R. (1973) Male-Female Wage Differentials in Urban Labor Markets. International Economic Review, 14, 693-709. https://doi.org/10.2307/2525981

[21] Blinder, A. (1973) Wage Discrimination: Reduced Forms and Structural Estimates. Journal of Human Resources, 8, 436-455.

[22] Tello, C., Raúl, R. and Manuel, A. (2012) Changes in Wage Structure in México Going beyond the Mean: An Analysis of Differences in Distribution, 1987-2008. Working Paper, 1-43. https://doi.org/10.2139/ssrn.2060555

[23] Popli, G. (2013) Gender Wage Differentials in México: A Distributional Approach. Journal of the Royal Statistical Society, 176, 295-319. https://doi.org/10.1111/j.1467-985X.2011.01031.x

[24] Arceo Eva and Raymundo Campos (2014) Evolución de la brecha salarial de género en México. El Trimestre Económico, 323, 619-653.

[25] DiNardo, J., Nicole, F. and Lemieux, T. (1996) Labor Market Institutions and the Distribution of Wages, 1973-1992. A Semiparametric Approach. Econometrica, 64, 1001-1044. https://doi.org/10.2307/2171954

[26] Rodríguez, R. and David, C. (2014b) Análisis de la discriminación salarial por género en Saltillo y Hermosillo: Un estudio comparativo en la industria manufacturera. [Analysis of Gender Wage Discrimination in Saltillo and Hermosillo: A Comparative Study in Manufacturing.] Nóesis, 46, 80-113. https://doi.org/10.20983/noesis.2014.2.3

[27] Castro, D., Luis, H. and Natalia, Z. (2015) Discriminación salarial por género, en la industria manufacturera de la frontera norte de México en el periodo 2005-2011. [Gender Wage Discrimination in Manufacturing the Northern Border of Mexico, in the Period 2005-2011.] Nóesis, No. 47, 50-80.

[28] Hanson, G.H. (2005) Globalization, Labor Income, and Poverty in Mexico. NBER Working Paper Series, 1-50.

[29] Gutiérrez, L. (2008) La distribución del ingreso en México: un análsis regional 1990-2004. [The Distribution of Income in Mexico: A Regional Analysis 1990-2004.] Problemas del Desarrollo. Revista Latinoamericana de Economía, No. 39, 139-163.

[30] Koenker, R. and Gilbert, B. (1978) Regression Quantiles. Econometrica, 46, 33-50. https://doi.org/10.2307/1913643 
[31] Koenker, R. and Kevin, H. (2001) Quantile Regression. Journal of Economic Perspectives, 15, 143-156. https://doi.org/10.1257/jep.15.4.143

[32] Dueñas, D., Iglesias, C. and Llorente, R. (2015) Abordando la desigualdad de género. Empleo en técnicas de información y la comunicación y diferencias salariales por género en España. [Tackling Gender Inequality. Information and Communication Technologies Employment and Gender Wage Gap in Spain.] Ensayos sobre política económica, 33, 207-2019.

[33] Mincer, J. (1974) Schooling, Experience, and Earnings. National Bureau of Economic Research, Columbia University Press, New York. 